wird bei $100^{\circ} \mathrm{C}$. getrocknet und gewogen; sein Gewicht, durch 3,8 dividirt, zeigt die entsprechende Menge wasserfreies kohlensaures Kali an.

Um in dem alkoholischen Filtrate das Natron zu bestimmen, destillirt man den Weingeist $a b$, nimmt den Rückstand mit wenig Wasser auf und dampft zur Trockne ein. Das pikrinsaure Natron Iässt sich von der beigemengten überschüssigen Pikrinsäure durch Ausziehen mit Benzol befreien. Das Gewicht des bei $100^{\circ} \mathrm{C}$. getrockneten pikrinsauren Natrons, durch 4,736 dividirt, gibt das entsprechende wasserfreie kohlensaure Natron an.

Quantitative Belege theilt der Verfasser nicht mit.

Zur Trennung des Zinks vom Cadmium und zur Bestimmung des letzteren. Kupfferschläger*) hat versucht, das Cadmium dadurch niederzuschlagen, dass er Magnesiumblech in die Lösung der Sulfate, Acetate oder Chloride der beiden Metalle eintauchen liess. Es gelang ihm jedoch nicht auf diesem Wege befriedigende Resultate zu erzielen, indem einerseits sich Zink neben Cadmium ausschied, andererseits auch nach längerer Einwirkung Cadmium in Lösung blieb.

Mit gutem Erfolg wandte der Verfasser dagegen folgendes Verfahren an:

Die neutrale Lösung der schwefelsauren Salze wird durch Kochen von Luft befreit, in ein nicht fest verkorktes Gefäss gegeben und ein blanker Zinkstreifen in die Flüssigkeit gestellt. Nach beendeter Reaction filtrirt man das gefällte Cadmium ab, wäscht es zuerst mit ausgekochtem Wasser, dann mit Alkohol aus, trocknet es bei Luftabschluss und wägt es; zur Controle kann man den Gewichtsverlust des Zinkstreifens bestimmen.

\title{
Ueber die Bestimmungsformen des gefällten Schwefelkupfers.
} Die von Ulrici**) empfohlene Ueberführung des Niederschlags in ein Gemenge von Kupfersulfür and Kupferoxyd ***) durch Glühen bei beschränktem Luftzutrittt hat schon $\mathrm{Busse}$ †) als unzulässig erkannt und auf die gleichzeitige Entstehung von Kupferoxydul und schwefelsaurem Salz hingewiesen.

A. Guard $\uparrow$ ) hat nun auf's Neue die Angaben Ulrici's einer Prüfung unterworfen. In Uebereinstimmung mit $\mathrm{Busse}$ erklärt er das

*) Bull. soc. chim. de Paris 35, 594.

**) Journ. f. prakt. Chem. 107, 110 . - Diese Zeitschrift 8, 466.

***) Kupfersulfür und Kupferoxyd haben denselben Procentgehalt an Kupfer.

†) Diese Zeitschrift 17, 55 .

††) Scient. Americ. 45, 357. - Chemiker-Zeitung 5, 979. 
Verfahren für nicht anwendbar zur Bestimmung des Schwefelkupfers, da das gebildete Kupferoxyd sich nach folgender Gleichung weiter zu Oxydul umsetzt:

$$
2 \mathrm{Cu}_{2} \mathrm{~S}+6 \mathrm{CaO}=\mathrm{Cu}_{2} \mathrm{~S}+4 \mathrm{Cu}_{2} \mathrm{O}+\mathrm{SO}_{2} .
$$

Nach Hempel*) lässt sich das gefällte Schwefelkupfer durch Glühen in dem von ihm beschriebenen Gasofen mit Oxydationsvorrichtung vollständig in Oxyd überführen. Dasselbe glaubt T. Morrel1**) zu erreichen, indem er den Niederschlag zuerst für sich, dann unter Zusatz von etwas salpetersaurem Ammon mehrmals vorsichtig über der gewöhnlichen Lampe glüht, oder indem er nach dem Befeuchten und Erwärmen des Schwefelkupfers mit wenigen Tropfen rauchender Salpetersäure gepulvertes kohlensaures Ammon zufügt und zwei- bis dreimal glüht.

\section{Chemische Analyse organischer Körper.}

\section{Von \\ W. Fresenius.}

1. Qualitative Ermittelung organischer Körper.

Zur Unterscheidung primärer, secundärer und tertiärer Alkohole und Alkoholradicale haben früher V. Meyer und L. Locher***) sehr charakteristische Farbenreactionen angegeben. Dieselben treten aber nur bei den Verbindungen mit niedrigem Kohlenstoffgehalt ein. H. Gutknecht $\dagger$ ) hat Versuche darüber angestellt, bis zu welchen Gliedern der Alkoholreihen die Reactionen noch zu beobachten sind. Er fand, dass die Reaction für secundäre Alkohole nur bei Propyl-, Butylund Amylalkohol eintritt, von den primären Alkoholen zeigt dagegen noch der Octylalkohol die Reaction und wahrscheinlich werden das auch noch höhere Glieder dieser Reihe thun. Es standen dem Verfasser aber zur Prüfung dieser Ansicht keine derartigen Verbindungen zur Verfügung.

Ueber Atropin, Daturin, Duboisin, Hyoscyamin und Hyosein ist eine ganze Reihe von Abhandlungen von A. Ladenburg ††) (zum Theil

*) Diese Zeitschrift 18, $4: 07$.

**) Amer. chem. soc. 1880, II, 145. - Ber. d. deutsch. chem. Gesellsch. zu Berlin 13, 1886.

***) Diese Zeitschrift 14, 371.

†) Ber. d. deutsch. chem. Gesellsch. z. Borlin 12, 622 .

††) Ber. d. dentsch. chem. Gesellsch. z. Berlin 12, 941; 13, 104, 254, 257, $380,607,909,1549 ; \mathbf{1 4}, 1870$. 